\title{
Examining the relationship of C. S. Peirce's semiotic and D. Winnicott's transitional phenomena and playing
}

\author{
Um exame da relação entre a semiótica de C. S. Peirce e os fenômenos transicionais e \\ o brincar de D. Winnicott
}

\author{
Paulo Duarte Guimarães Filho \\ Psicanalista - membro da Sociedade \\ Brasileira de Psicanálise de São Paulo - Brasil \\ pduartegf@uol.com.br
}

\begin{abstract}
First, it is considered how the possibilities of relationships between Peirce's philosophy and psychoanalysis have been the subject of papers by philosophers and psychoanalysts. The conceptions of Donald Winnicott about transitional objects, transitional phenomena and playing are pointed out as of particular interest for the study of these relationships, due to their links with Peirce's philosophy. Then, it is indicated how Winnicott refers to the relations of symbolization (not in Peircean terms) with the objects and transitional phenomena and how a "full understanding" of the processes of symbolization could contribute to the knowledge of those phenomena. We examine how Peirce's semiotic has elements that help understanding what is called "symbolization" by Winnicott. In this way also allowing the discrimination of the semiotic aspects present in the transitional objects, transitional phenomena and playing; thus expanding on some dimensions of the meaning of Winnicott's conceptions. These issues are further illustrated in the clinical cases of "Edmund" and "Diana", presented by Winnicott and also in two other clinical situations.
\end{abstract}

Keywords: Peirce. Semiotic. Winnicott. Transitional objects. Transitional phenomena. Playing. Symbolization.

Resumo: Inicialmente, considera-se como as possibilidades de relaçôes entre a psicanálise e a filosofia de Peirce têm sido objeto de trabalbos de filósofos e psicanalistas. São destacadas as noções de Winnicott sobre os objetos e fenômenos transicionais e o brincar, como uma área de particular interesse para o estudo dessas relações, dadas suas ligações com a filosofia de Peirce. É, então, indicado como Winnicott faz referência às relações da simbolização (não em termos peircianos) com os objetos e fenômenos transicionais e indica como um "fully understanding" dos processos de simbolização podem contribuir para o conbecimento desses fenômenos. Considerando essa manifestação de Winnicott, é examinado como a semiótica de Peirce contém elementos que auxiliam o entendimento do que é chamado de "simbolização", por Winnicott. Desse modo também contribuindo para a discriminação dos aspectos semióticos presentes nos objetos e fenômenos transicionais e no brincar, permitindo, assim, uma 
ampliação de algumas dimensões da significação das concepções de Winnicott. As questões referidas são examinadas amplamente nos casos clinicos de "Edmund" e "Diana", apresentados por Winnicott e também em outras duas situações clínicas.

Palavras-chave: Peirce. Semiótica. Winnicott. Objetos transicionais. Fenômenos transicionais. Brincar. Simbolização.

\section{Introduction}

The different forms of representation of our emotional experiences have been one of the main foci in psychoanalytical studies. Some of these forms of representation, such as language and those corresponding to the less precise term of symbolism, operate in broader areas of the human experience and are studied in different disciplines. A recognized and significant contribution from these studies of particular interest to psychoanalysis is by the North-American philosopher Charles Peirce (1958), especially his contributions to semiotics. The relationship between psychoanalysis and Peirce's philosophy has been discussed in several papers published by philosophers (COLAPIETRO, 1989, 1995, 2006, and 2008; and VER EEKE, 2000) and psychoanalysts (MULLER, 1996, and 2006; SALOMONSSON, 2007; STEINER, 2007; and FISCHBEIN, 2011). Through these two areas of study, we pay attention to something that until now had not been properly explored in the psychoanalytic literature, which is the fact that some of the most original and creative concepts by authors as prestigious as Winnicott and Bion have a lot in common with the semiotic aspects studied by Peirce. Winnicott, with his conceptions of transitional objects and transitional phenomena, and Bion, through alpha function, clarified and contributed to the recognition of how certain types of signs are associated with emotional experiences and, from the beginning of life, participate in processes to create meanings for these experiences.

In order to facilitate the understanding of the semiotic elements in Winnicott's and Bion's works, particularly Winnicott in the present paper, as Bion has been the subject of another article (GUIMARÃES FILHO, 2011), it will be worth considering something that Colapietro mentioned in a chapter titled "The Relevance of Peirce's Semiotic to Psychology". Colapietro says:

The various ways in which our cognitive endeavors become
arrested or frustrated is a topic for the psychology; however, to
explain the failure of cognition presupposes an understanding
of the ideal toward which and the norm by which cognition
develops. (COLAPIETRO, 1989, p. 53).

This excerpt is part of a chapter in which Colapietro specifically examines Peirce's positions regarding the relations of semiotics with psychology and, in our opinion, summarizes the crux of the matter. In this passage, Colapietro emphasizes how the more universal aspects of the nature of the signs and the way they function to constitute our cognition, according to Peirce's thinking, would comprise a foundation of enormous value to investigate these processes on a psychological level and, in the 
broad sense that we use this term, also on a psychoanalytical level. We emphasize this statement, as it helps us recognize that Winnicott and Bion have dealt with this issue. These authors were able to identify the role of certain signs in expressing and dealing with emotions, but they were also turned to what we could call a philosophical level of their conceptions about signs, i.e., the degree of universality that these conceptions might have. Several examples are available in regard to Bion (1992), but since he is not the subject of our analysis at this time, we will only recall his writings published posthumously in "Cogitations," in which he deals with various issues related to the philosophical level, with frequent references to authors such as Hume, Poincaré, Whitehead, Bradley, Braithwaite, and several others.

\section{Peirce's semiotic and Winnicott}

In Winnicott's work, on which we will focus our attention, he expresses his interest in the relations of transitional objects with the more universal theme of symbolism. Winnicott's interest in this topic was such that he used it as a title for an important chapter that he wrote about transitional objects (1971). Regarding transitional phenomena in general and playing in particular, it is not difficult to verify that Winnicott also focused on the level of universality of these manifestations, although he does that more descriptively, rather than seeking a conceptual discrimination of these phenomena.

While raising these points, we must emphasize that one should not assume Winnicott or Bion to be philosophers, which they were not, but rather, to distinguish that the phenomena that they investigated have important implications for the philosophical dimension. The recognition of these proximities may help us understand possible similarities between Winnicott's and Peirce's conceptions regarding transitional objects. We will present how Winnicott (1971) treats elements that contribute to playing, which he views as important, and clinical situations that he presents in this regard by examining his "Diana's case." Since Winnicott did not develop a detailed theorization regarding the role that the signs would have in playing, we will consider in this paper areas in which Peirce's semiotics may have contributed to his work. In a Conference at the Squiggle Foundation about the "Playing" in Winnicott, André Green mentions something valuable:

In wanting to put play on the side of health, Winnicott also wanted to relate it to a satisfactory mother-infant relationship based on trust and developing into group relationships. According to my ideas, playing belongs to a group as well as psychic phenomena-including dreaming, fantasizing, forging fictions, and myths. If I have to find a trait to define it, I shall have to turn not to a Winnicottian concept, but to a Bionian one. I would make the hypothesis that it could be one of the applications of Bion's "alpha" function. And just as Bion created the symbol " $K$ " for Knowledge, he also created "-K" as its complement. I believe that play, apart from its emotional value, is a form of thought (like the dream) or of knowledge that, according to some patients is a form of not knowing, In the same way, just as treacherous, cruel, and destructive plays are 
forms of not-playing, they can also be seen as negative playing. (GREEN, 2005, p. 12).

We may understand from the excerpt above that Green may be pointing out that we need a theoretical system to conceptualize the signs in order to think about manifestations of playing. In this case, his suggestion is Bion's alpha function. We mentioned before how we will use Peirce's semiotics and, through this, we will show how specific elements of signs and semiotic processes operate during play, to reach what Green emphasizes in a more general way as the production of knowledge, or something that is not knowledge.

The basis for what we pointed out above is Winnicott's (1971) conception of the transitional object, one of his major contributions to psychoanalysis. These objects are relatively simple manifestations that tend to occur at the beginning of life and whose relevance to mental development was apprehended by Winnicott, as a result of his position as a pediatrician-psychoanalyst. He asserts that there is a relationship between the meaning of manifestations occurring in early development, such as finger or pacifier sucking, and very special links that occur later on with certain objects, which Winnicott named transitional objects. These are well-known objects of different types, such as a piece of cloth, or a teddy bear; the child has a very peculiar bond with such objects, requiring their company in certain occasions, such as when leaving the house or going to sleep. We will refrain from going into details about the characteristics that Winnicott found in transitional objects; we will instead highlight some aspects of these objects in which we may find a clear proximity to Peirce's philosophy. This parallel is associated with the fact that transitional objects function with a quality of concrete representation and as something with great emotional importance to the little child. As we present below, the proximity with Peirce on this issue occurs because his philosophy distinguishes how cognitive processes have modalities of object representation through signs directly connected to the objects they represent-which he named icons and indices_-showing, therefore, a striking parallel with Winnicott's transitional objects and phenomena. Winnicott identified the importance for the psychic development that establishing this representation-presence has when he observed impairment in the psychic development in cases not using transitional objects.

Despite the common aspect mentioned above between Winnicott's representations (transitional objects) and Peirce's representations (iconic and indexical signs), these are concepts that operate at different levels - the psychological level in Winnicott, and the philosophical one in Peirce. Therefore, it becomes necessary to examine the extent to which the more generalized aspects of Peirce's ideas, given their philosophical nature, could contribute to Winnicott's elaborations. Before reaching this examination, we need to present some basic information about Peirce's ideas.

\section{Some elements of Peirce's philosophy}

At this point, our purpose is not to offer a general and systematic presentation of Peirce's philosophy (1958), but rather, to refer to some of its basic aspects which, in our experience, have been useful in thinking about different issues in 
the psychoanalytic area. We have already mentioned above the central role of Peirce's contributions for the constitution of the meaning of the phenomena that are part of our experiences. A basic element here is his mention of only three modalities in our cognitive relations with the phenomena. Peirce distinguished three basic forms (or categories) through which these relations occur, and named them firstness, secondness, and thirdness. Although this is a peculiar terminology, it is not difficult to follow its meaning. Firstness refers to the first contact that we have with the experiences, impressed by their sensitive qualities. Some authors (IBRI, 1992) mention the "presentness" and an "immersion" in the actuality of the experience, regardless of other distinct aspects. At the same time, this "first" does not exist in isolation, without the otherness of the phenomena, of objects different from the observer, which Peirce named secondness. As a result, he highlighted the etymology of the Latin word, "obiectum," the one who objects, who opposes the observer.

We could think of a simple and concrete example of these notions by imagining someone having his first contact with a flower, a rose for example. His immediate contact would be with the sensitive qualities of the flower-its shape, size, color, smell, texture, etc. This person could also pick the rose up, feel its weight, corporeity, and character of being another, different from the observer. According to Peirce (1958), both categories above are always present in our immediate contacts with the phenomena. If these contacts are no longer immediate, we establish a relationship with their continuity; thus, it becomes necessary to unite what happens in this succession, by having a "third" that brings together the ensuing aspects of firstness and secondness, of which Peirce named thirdness. In the example of the rose, the contact would no longer be immediate when the person observes that the rose grew from a bush, had different growth stages, and reached a point of special beauty, hence being used for decoration, etc. Through these observations, the person would become aware, as indicated by Peirce, of behaviors or habits of the rose; habits that constitute what the rose is, and lead to the formation of the concept of "rose". Therefore, there is a contact with the temporal continuity of aspects of firstness and secondness, corresponding to what Peirce named thirdness.

We mentioned above how, according to Peirce, our relations with the objects are established so that these objects become known, through what he called semiosis. The other two elements of the triad that he conceived as comprising the semiotic processes are the sign and the interpretant, both highly important in psychoanalysis. In the case of Winnicott's transitional phenomena, we have already pointed out how much they have to do with Peirce's conceptions, particularly his signs. According to Peirce, the different modalities of experiencing the phenomena-firstness, secondness, and thirdness - have signs that correspond to them according to their relationship with the objects. In the case of firstness, the signs representing it were designated by Peirce as icons, and are characterized by the fact that they represent their objects by similarity. Without using Peirce's terminology, evidently, Winnicott turns toward something in this direction by suggesting that transitional phenomena are linked to the baby's prior experiences of sucking the finger or a pacifier. These are good examples of iconic signs of the breast, i.e., representation of the breast by similarity.

As for secondness (the characteristic of being another of the phenomena), this may appear through different facets of the phenomena, constituting the signs that Peirce named indices. Continuing to use Winnicott's notions to offer examples 
regarding Peirce, in the case of the indices, it is possible to follow how the baby establishes contact with different aspects of his mother, her face, her speech, her smell, her skin, etc.; all these elements may be considered her indices. This example is helpful in adding the information that iconic aspects of the breast predominate in the finger and pacifier, while in the piece of cloth or the teddy bear, there is a more global relationship with the mother figure or with the breast, and that such objects are indices, thus representing the mother as a whole through one of its parts; in the case of the blanket, for example, the index-part corresponding to tactile sensation constitutes the sign-object. We only use here the transitional object as an example of an index, but it is already possible to mention in advance that Winnicott had distinguished how these indexical aspects allowed a feeling of possession of a valuable object, becoming part of what he named "not-me." The importance and role of these aspects are pointed out by Winnicott when he gives examples of lack of establishment of a transitional object and, associated with that, the impossibility of a concrete separation from the mother. Taking this into consideration, one of Winnicott's fundamental and extraordinarily enlightening notions may be expressed in Peirce's semiotic terms: the value of experiencing a sign that is partly a sign but also partly an object, so that this could later contribute to the development of a broader process of the use of signswithout aspects of the object in it, the symbols of Peirce - to constitute meaning.

This process refers to thirdness, and the signs corresponding to that, according to Peirce, are the symbols. Unlike icons and indices, the symbol is a sign without a direct link to its objects, representing them through a mediator, a third element; in the given example, the word "rose" (an expression of its conception) is a symbol of the rose.

\section{Transitional objects, Transitional phenomena, Symbolism, Winnicott, and Peirce}

By now, we have enough elements to obtain a more clear understanding of how Peirce (1958) may contribute to Winnicott (1971) in the area that is being studied. To some extent, Winnicott (1971) himself formulated this question, which he wrote in a section with the subtitle: "Relationship of the transitional object to symbolism" in a chapter of his known "Playing and Reality." We will soon present his theory regarding this, but we must first stress that through the concept of transitional objects, Winnicott addressed ways to constitute meanings from experiences at a psychological level, while realizing that this constitution also had a more general dimension. He gave indications in this respect when he mentioned that for a better understanding of the transitional phenomena, there was something that needed to be more widely known about what he called "symbolism." What we are examining in this paper is how, by using another terminology, not only that of the study of "symbolism," but of signs in general, Peirce's philosophy and in particular his semiotics, contains something of a broader knowledge about what Winnicott named "symbolism." By recognizing these points, we will be able to follow Winnicott's recommendation about symbolism and verify the extent to which discriminating between different types of signs in Peirce's philosophy may contribute to our understanding of transitional objects and phenomena.

To proceed in this direction, we must first mention a passage that Winnicott wrote in The relationship of the transitional object with symbolism: 
It is true that the piece of blanket (or whatever it is) is symbolical of some part-object, such as the breast. Nevertheless, the point of it is not its symbolic value so much as its actuality. It's not being the breast (or the mother), although real, is as important as the fact that it stands for the breast (or mother).

When symbolism is employed the infant is already clearly distinguishing between fantasy and fact, between inner objects and external objects, between primary creativity and perception. But the term transitional object, according to my suggestion, gives room for the process of becoming able to accept difference and similarity. I think there is use for a term for the root of symbolism in time, a term that describes the infant's journey from the purely subjective to objectivity; and it seems to me that the transitional object (piece of blanket, etc.) is what we see of this journey of progress towards experiencing.

It would be possible to understand the transitional object while not fully understanding the nature of symbolism. It seems that symbolism can be properly studied only in the process of the growth of an individual and that it has at the very best a variable meaning (WINNICOTT, 1971, p. 6-7, my emphasis).

In the first paragraph of this quote, we may observe a relationship with elements in Peirce's semiotics that identify some aspects of transitional objects recognized by Winnicott. We may also consider that the more general notion of "symbolism" that Winnicott had available was insufficient for him to formulate properly what he introduced at that time. In the excerpt above, Winnicott mentions that it would be correct to say that a piece of blanket was a symbol of a partial object such as the breast, but that the issue was not its symbolic value but rather, its "actuality". In other words, he recognized the role of the transitional object as representing the object by having this characteristic of the conventional symbol, but at the same time, having a characteristic that is not part of the conventional notion of the symbol, of having something of the reality of the object. It is not difficult to think that there is a way out of this conceptual limitation if we use the terms previously seen in Peirce's semiotics. We will then talk about signs, two of them more directly-icons and indices, since they represent their objects by having a direct link with them. We can go back to what we mentioned earlier by giving examples of how aspects of iconic and indexical signs are present in transitional objects. Taking the pacifier as an example of such objects, we mentioned that it functions as an iconic sign of the breast, i.e., it represents the breast by similarity while having at the same time something concrete of the object; it is then a sign that represents the object and at the same time has something concrete of the object. Likewise, the piece of blanket as a transitional object is an indexical sign that represents the maternal object through one of its parts, in this case, the tactile contact with the maternal body; therefore, it is also a sign that represents the object and has something of its reality.

The material presented above allows us to visualize one of the types of contributions from Peirce's philosophy regarding transitional objects. This contribution occurs because his philosophy, particularly his semiotics, enables a more precise identification of characteristics of the signs present in transitional objects and their 
operation at a more specific level of the psychological development. Another very relevant consequence of what we considered above is the fact that if transitional objects have such a high level of agreement with what we observed in Peirce's semiotics, this compatibility implies support on a philosophical level of enormous epistemological value to Winnicott's formulations and, in a broader sense, to this area of theory in psychoanalysis.

At this time, we must note that one of the main values of Peirce's philosophy is the fact that it is not limited to identifying the nature of different types of signs, as discussed before, but also to distinguish the processes through which they establish meanings, which he named semiosis. We considered above how a semiotic process would occur in the apprehension of a meaning, through the example of the conception of a rose. Without using the term semiosis, Winnicott somewhat addresses this issue, especially when inquiring about the relationships of transitional objects with symbolization, as noted previously. One way in which the English author formulates this issue may be seen in the second and third paragraphs of the excerpt presented above. There, in a broad manner, Winnicott points out the role of transitional objects as a "root" of symbolism ("I think there is use for a term for the root of symbolism in time, a term that describes the infant's journey from the purely subjective to objectivity" (WINNICOTT, 1971, p. 7, my emphasis)). He explains that this "root" is the transitional object. We have already pointed out the extraordinary value of the discovery that the transitional object at the same time represents and encompasses something from the object. For this reason, the transitional object contributes to the further use of the signs, which Winnicott named "symbolism," in which an object is represented without its presence. We have already seen how Peirce's conceptual tools can contribute to distinguishing what would be part of this "root of symbolism-transitional object" that Winnicott refers to; these tools could clarify how the iconic and indexical aspects of signs participate in the creation of meanings. These Peirce an contributions are perhaps even more important in regard to one thing that Winnicott deals with: the possibility of using signs to properly represent the object, which he refers to as "symbolism." Winnicott recognizes and deals with the existence of such processing of signs to create meanings, but does not clarify the dynamics of this semiosis in the way Peirce's work has done. Given the relevance of this issue, we will try to facilitate understanding regarding the value of its implications by using a clinical situation presented by Winnicott (1971) and another by Freud (1920), which is the well-known cotton-reel game played by his grandson.

Winnicott's patient (1971), Edmund, is a child of about 2 to $2 \frac{1}{2}$ years of age characterized as not accepting substitutes for his mother, i.e., not using transitional objects. During the interview, Edmund becomes entertained with some toys, which he alternates with going to his mother's lap. At one point, Edmund becomes interested in a rope that was among the toys and uses it as if it were a wire connected to an outlet on his mother's thigh. The rope is used as a concrete way to maintain a connection with the mother.

It is very useful to compare and observe the difference between the rope and the string used in the cotton-reel game of Freud's grandson (1920). In the latter, the reel is pulled by the string on a motion of removal and return to the child, and is accompanied by "fort" and "da" (disappearance and return). Unlike the restricted role of Edmund's rope, it is a more expressive example of a transitional 
phenomenon in Winnicott's terms, while also serving as a much clearer visualization of an important semiotic process in Peirce's terms, because it becomes quite evident how the string and the reel work as iconic and indexical signs of disappearance and reappearance, referring to the mother, articulated with the symbolic linguistic signs, "fort" and "da" (disappearance and return). They represent the mother's comings and goings and may be used without the presence of the object.

\section{Transitional phenomena, playing, Winnicott, and Peirce}

What we observed above in Freud's grandson playing is very illustrative of how a discrimination of Peirce's signs would enable us to identify how these signs participate in a situation such as that of the cotton-reel game, leading to the possibility of representing a separate object, usually designated as symbolization in psychoanalysis. In this article, we consider how this type of discrimination may contribute to clarify Winnicott's (1971) particular focus of interest: the relationship between transitional objects and symbolism and playing. Following what Winnicott said, we believe that one of the most significant aspects present in these primordial relations with the transitional object (and which is carried over to the playing) is creativity, the possibility of creating an object capable of simultaneously representing something and being valuable in itself. This is associated with the development of another aspect highlighted by Winnicott, which is confidence in the self and in the objects - essential factors for the existence of willingness to live. Winnicott (1971) also distinguished the possibility of sharing, which is present in playing, as being indicative of transitionality, which will have an equally prominent role in cultural manifestations.

One thing that seems to be part of the importance of playing (which has to do with the points highlighted above by Winnicott), but was not included more directly in Winnicott's formulations, is what Green's pointed out as the role of playing as a form of thought and this, in terms of Peirce, could be considered as its semiotic role in the expression and handling of emotional experiences. The presence of these elements in the cotton-reel game provides a very clear example of how this occurs.

We will now present some clinical situations considering how the use of Peirce's notions about signs and semiosis could contribute to the understanding of aspects of playing. We will then begin with Diana's case, which Winnicott (1971) used to illustrate his ideas about the importance of playing in the chapter "Playing: $a$ theoretical statement," which is part of "Playing and Reality." We will also comment on two other clinical materials presented in Seminars at the Brazilian Society of Psychoanalysis of São Paulo, "Beto," by Alessandra Gordon, and "G.", by Roberta Abreu Sodré.

\section{Diana}

Let us move on, then, to the case of Diana, a 5-year-old child. The appointment was not for Diana herself, but for her mother who was having difficulties with another child who was mentally defective and had a heart problem. Winnicott picked up on the fact that there was no proper reason for Diana to be brought to the appointment and that the mother had likely brought the daughter as a support. 
Winnicott also became aware of the child's involvement in the situation when she divided her attention between playing and his conversation with the mother. This occurred, for example, when Diana left the toy aside and referred to the "hole" that her brother had in his heart, when his disease appeared in the conversation between both adults. A similar form of participation occurred at another moment when the mother cried, which led Diana to leave the toy aside again and show apprehension. In this instance, Winnicott sought to soothe her, saying that her mother was crying because of her brother's illness. In addition to these details, there are also notes from a second interview in which Diana was not present, when the mother revealed information regarding something that had shown up in Diana's playing: the father stimulated the daughter to show maturity, revealing a special satisfaction when she did so.

The information presented above refers to very intense emotional situations experienced by Diana. Thus, we could examine how such situations were related to her playing and what would have been present in this play that was so meaningful to Winnicott (1971), since he chose it to illustrate the importance of playing when he addresses this issue in "Playing and Reality." We believe that the fundamental point to which Winnicott refers to is that playing tends to function as a means of expression and an attempt to deal with situations that create intense emotional mobilization. We will not repeat the entire description by Winnicott about his encounter with Diana and what she played with but rather, recall one of the most significant moments in her play in which she put the little animals under her clothes, simulating a pregnancy and caring for the two "babies." This demonstration, along with the father encouraging the daughter to show maturity, seems to have led Winnicott to think that Diana would seek a premature development of her ego and identification with her mother when she participates in the problems related to her brother's disease.

Let us now examine how the elements of Peirce's semiotics may offer additional clarifications regarding Diana's manifestations. A very relevant point regarding this issue is the fact that playing has to do with something that was happening only at an affective level and this is represented in the playing. In Diana's case, her playing highlighted the representation of the pregnancy with the little toy animals and the babies' birth, which could be expressing something about the way she was affected and reacted to her parents' emotional mobilizations, especially those arising from what was happening with her sick brother. The contribution that we can derive from Peirce's conceptual tools is that they allow us to think that Diana was receiving and reacting to communications that occurred on firstness and secondness levels. We refer to the mother's manifestations of distress and disorganization before the sick child, her seeking Winnicott's help, taking Diana as a support, crying during the appointment, etc. Through what appears in her play, we may infer that the appreciative attitude of the father due to the daughter's signs of competence also lends to this emotional situation. It seems that these were the fundamental elements that led Winnicott to the most important conclusion about this play, as mentioned earlier, when he says that Diana's playing displayed her effort to seek a premature ego development and identification with her mother. As discussed above, Peirce's semiotic is valuable to our understanding of this passage as a constellation of emotional elements and their representation in an example of play. The semiotic 
notion to be used here is that of the iconic sign that function as such due to its similarity with their objects, which in Diana's case was the representation of the pregnancy and care of the little children, in which she was able to express her mobilization as a response to the situation presented above.

In a segment of Winnicott's excerpt (1971) about this situation, we have a valuable example of how Peirce's notion of semiotics helps us understand the facets of a clinical situation. This appeared in Winnicott's comment about the moment in which Diana sought to participate in the mother's conversation referring to the brother's illness, in which Diana says that he had "a hole" in his heart. Winnicott's subtle comment was how the child could say something about this disease, but not about the brother's mental deficiency. This comment is very valuable to help us think that it is not only about the brother's mental impairment that Diana could not say something, but also about the entire emotional situation in which she was involved due to his disease, which she was unable to speak about, but was able to play about, as discussed earlier.

We could ask at this point: what is the reason for this difference? And also, how would Peirce's notions help us discriminate what could be occurring in her being allowed to play but not to speak? Let us start with the most explicit manifestation of Diana in which she can talk about "the hole" in her brother's heart. This is an emotionally charged situation in which the child, as we discussed, is in contact with manifestations of firstness and secondness transmitted by her parents and by her own experience with her brother. These elements are also present in the iconicindexical figure of the heart with a hole. In the case of the heart disease, these modalities of experiences with their corresponding signs can contribute to a full semiotic process, in terms of Peirce, when they are completed by an articulation of these elements, which will constitute thirdness, through a symbolic sign-Diana stating that her brother had "a hole" in his heart.

The other situation experienced by Diana, the one mentioned before in which she can play with but not speak about, involves an intense emotional mobilization of the parents with their direct effect on her. Peirce's philosophy enables us to understand more clearly how these intense mobilizations (which exist primordially at levels of firstness and secondness) will not lead to a broader process of gaining meaning through characteristics of thirdness, in terms of Peirce, but to the parents' reactions, especially regarding Diana, as seen in previous comments. We also examined the aspects of the child's play, mobilized by these emotional constellations, which can only occur by means of iconic-indexical signs, but not by symbolic ones.

\section{Beto}

Beto's clinical situation will be particularly valuable for our understanding of how Peirce's semiotics provide conceptual elements that help to recognize the nature of a very peculiar form of attack to thinking that is different from those studied by Bion (1967) in this area. This happens in initial moments in the analysis in which mobilizations at levels of firstness and secondness occur in an attempt to obstruct possibilities of thirdness. The patient, Beto, 8-years-old, has the following characteristics referred to by the Analyst: "Likes to annoy others, hits his friends frequently, and has difficulties in accepting boundaries at home and at School." Beto 
has a sister who is 6 years-older than him and a half-brother, from his father's first marriage, who is around 20 years-old. Other relevant information includes the fact that the parents were separated until the mother became aware that she was 2 months pregnant, which led them to live together again. In early pregnancy, while unaware of being pregnant, the mother underwent breast and abdomen plastic surgery. Another fact about the mother was that she was very involved with her professional executive life, and had limited availability to her children. Beto had previously undergone two years of speech therapy, as well as psychotherapy, which was interrupted because he disliked the psychologist. We transcribe below two segments in which the Analyst describes Beto's playing, corresponding to the beginning of the treatment and a period that follows soon after that. The manifestations of the patient's playing will be the target of our comments. The transcripts are as follows:

1st excerpt: $\quad$ At the beginning of his analysis, Beto lived in a world of many fights, with robots, monsters, etc. He would come to the sessions and stage the fights or draw the characters. He could hardly bear when I spoke something: "Here you come with your little phono talk[...]." ${ }^{1}$ So, I went on playing and made myself present through the playing, noticing that be would leave calmer than when be entered the sessions.

2nd excerpt: After this phase, we went through a period of training, in which I had a known trainer, Muricy Ramalho, coaching the player-goalie Beto. We were part of a team with other players; we had someone, Arnesto, who belped us arrange the things in the 'club' (the room). And so Beto was able to help me put away the toys. Arnesto was also someone with whom the coach talked in a loud voice, since Beto did not like to talk. And at the end of practice, we would have a game.

Beto's playing occurs in a psychoanalytical setting, unlike Diana's situation. Despite this difference, it is not difficult to perceive how the playing described at the beginning of the treatment, "[...] in a world of fights, with robots, monsters, etc." has to do with the emotional life of the patient who "[...] likes to annoy others, beats his friends frequently [...]". Another characteristic of Beto's functioning, which is very significant in this context, is that he is unable to accept when the Analyst speaks, and he says: "Here you come with your little phono talk [...]". In this situation, we might think that we have a playing closely associated with elements that appear with intense emotional charge in the patient's life, which is his aggressiveness. The events in his life, possibly associated with his playing, are not as close as in Diana's case. Taking into account the elements reported above by the Analyst and those that appeared in the second excerpt of the transcribed material, we might formulate some conjectures: in his early experiences, has Beto been confronted with objects experienced as hostile, such as frustrations with a mother who was not very available? A much older sister who was feared or envied? When he faced these negatives experiences, did aggressiveness become his main way to react?

1 In Brazil, "phono" is a short form for speech therapist. 
We will refrain from following the analysis of the patient since this is not our focus at the moment, although it could probably offer us elements to reinforce some of these conjectures. Regarding our focus, which is to think about contributions from Peirce's semiotics to a clinical approach, there is a valuable element in Beto's attitude when he does not allow the Analyst to speak, mocking her with the expression: "Here you come with your little phono talk [...]" (it is worth recalling here that he received prior care by a speech therapist). It is not difficult to believe that this manifestation has to do with Green's observation (2005), mentioned earlier, that playing is a way of thinking, but to some patients, it is also a way of not thinking. In this case Green is also using Bion's concepts, particularly the alpha function and "K" and "-K," to define these manifestations. We recalled this observation since an approach to playing through the notion of alpha function draws parallels with Peirce's approach using semiotic instruments. We will soon examine how Peirce's notions will allow the identification of elements contributing to semiotic processes that either lead or do not lead to knowledge. Without using these terms, we observed that the firstness and secondness of the experiences that Beto probably went through led him to a frequent attitude of violence toward others, such as when he chooses to play in the form of fights, with its natural representation as superheroes battling monsters. It is not difficult to recognize these figures that predominated in the initial phase of the analysis as iconic-indexical signs representing the constellations of emotional clashes in which the child was involved. We have signs that the exaltation of these elements of firstness-secondness correlate with the dismissal of the value of elements of thirdness, which appeared clearly in his disdain to the "little phono talk [...]" and in him not allowing the Analyst to speak. It is very interesting to compare this situation with the one observed with Diana. With her, there was also a dimension of experiences at the level of firstness-secondness, which could lead to playing, but not to speaking. However, there was no clear conflict in regard to her operating at a level of thirdness such as with Beto. Peirce's philosophic tools, which we are using as a framework, not only allow a better visualization of the existence of and reasons for this conflict, but also assists us in following the developments that occur in regard to these aspects. This appeared in the other passage presented about Beto's manifestations, when this picture changed radically and the patient became interested in being guided by the soccer coach.

Before arriving at this point, it will be useful to go back to the passage that describes the initial moment in the analysis in which the patient had to enact fights and in some way dominate the Analyst by not allowing her to speak, although she observed that something was happening because Beto would leave the sessions "calmer than when be entered." We can imagine, then, that beside the firstnesssecondness related to the clashes, the patient also apprehended the qualities and indices of an object that showed some availability and did not react with violence or detachment. Thus, we might suppose that all of these things contributed to the emergence and expression (through the soccer coach) of the patient's need for an adult object to help his development. The interest and pleasure in violence was replaced by the desire to be part of a soccer team and have partners to live and collaborate with. It was fascinating to see the emergence of "Arnesto," who helped to clean up the room and agreed to talk to the Analyst. His figure contains the personification of functioning at the level of thirdness, through which he could not 
only put the room in proper order, but also the meaning of his experiences and with that, accept the use of speech-words (Peirce's symbols). In contrast, we had in this context an interesting but not surprising observation that Beto still disliked to talk and was required to double up as Arnesto to make this happen. After all, in Beto's "world" he learned to live with a predominance of firstness-secondness elements; when he moved to a universe in which thirdness was also included, it became an extraordinary change, with unknown and laborious novelties which, at that time, also required a new continent: Arnesto.

In the foregoing, we evidenced how Peirce's conceptual tools allowed us to identify elements that participated in a type of conflict with thinking and that, perhaps, had not been recognized as such in the psychoanalytic literature until now. In this sense, some of Beto's experiences were categorized at levels of firstness and secondness, with their respective iconic and indexical signs (the superheroes and fights during the sessions), working in opposition to the thirdness of the Analyst's speech with their respective symbolic signs ("here comes you with this little phono talk [...]"). We may consider some implications through the use of these tools if we recall another type of attack to thinking, studied by Bion (1967) in psychotic patients, which had a very relevant role in the development of his ideas. In fact, this was one of the observations that led Bion to conceive the alpha function, which is not operative in psychotics (in which alpha elements are not produced and beta elements prevail) and, according to Bion, cannot be used for thinking and learning from experiences.

An interesting point about what we examine here in terms of interrelations with Peirce is that Bion considered alpha function as a formulation not yet fully defined, and therefore, open to further investigation and clarification. While we are not discussing this issue in particular, we will use it to think about Beto's case, in which there might be another type of conflict with thinking, as stated above, which we were able to identify and formulate using elements of Peirce's semiotics to understand these clinical situations. What we verified there was not only restricted to recognizing the conflict; it also enabled us to distinguish developments that occurred in regard to Peirce's semiotics, when Beto became interested in having a soccer coach and using speech as a way of communicating with the Analyst; the gain in prestige becomes clear in modes of operation at Peirce's thirdness level, with the corresponding symbolic signs. Therefore, what we just observed is an example of the value that can be found by opening areas of investigation focused on the interrelations between semiotic elements developed within psychoanalysis and those that are part of Peirce's semiotics. Further, this probably conforms with Bion's suggestion that alpha function is a concept which needs more investigation.

\section{G.}

In this case, we also have a situation in which Peirce's semiotic tools may help us understand the nature of the changes that occurred in a child living in very adverse conditions by examining her playing. We will then be able to follow how playing with predominantly elements of firstness and secondness and their corresponding iconic-index signs will change into other types of playing with a greater presence of features of thirdness and its corresponding symbols. 
The patient, named G., is a 5- or 6-year-old child who had been sheltered for two years and had nine or ten other siblings who were also sheltered, of whom three or four were housed in the same shelter as her. According to the Social Worker, the children were sheltered because "the mother was a prostitute and the father was an alcoholic and unemployed" who later lost his paternal ownership over the children. Next, we will examine four manifestations of G.'s playing and the circumstances in which they occurred. Through them, we will have more information about the conditions of this child's life.

At the beginning of the treatment, the patient repeatedly played a memory card game called "mico" that consists of cards with paired figures that must be combined, in which the player who ends with the "mico" is the loser. The Analyst reports how this game served to bring G. gradually closer to her, but was interrupted due to a certain "accident." G.'s shelter also housed other children and, on a given day, one of them approached G. and the Analyst, indicating a desire to have the Analyst as her therapist. Without going into details of how this situation unfolded, it is important to say that it triggered an intense reaction in G., who during the following weeks no longer accepted to join the sessions. The Analyst became aware of G.'s sensitivity to this threat of yet another loss and recognized the importance of showing G. that she continued to be available. She would then remain in the waiting room with G., saying how she would stay there until the patient wanted to return to the sessions. G. only returned to the sessions after a long time had passed, requiring the help from an educator from the shelter, with whom she had a good relationship. The child agreed to go to the sessions with this educator, but would initially only play games with him, not allowing the Analyst to participate.

Following this period, when she returned to interact more with the Analyst, another kind of play emerged, in which her mobilization was quite clear in the sense of dealing with the blows and losses she had been subjected to. She created a type of play that would revert this situation. This is how, in the Analyst's words, this play occurred: G., with her gun, would shoot everything in the room, including me. Another play was when she would ask to throw the ball to her and then shoot the ball while I stood behind it, with some shots coming in my direction, without her disguising her anger. His stage there also appeared "[...] constructions with wooden blocks and towers. She built towers with the blocks, which then became 'castles.' These towers were built and soon after that, knocked down by ber blowing."

The observation of the different moments in this child's manifestations of playing, which contains clear connections with ongoing vital and emotional situations, serves as a very expressive example of the relevance of the role of playing. Thus, the play that we just described shows the emergence of hostility directed toward the Analyst, who was perceived as unsafe. These feelings were represented by gunshots aimed at the Analyst and constructions that were quickly destroyed. This child was trying, thus, to deal with the disadvantageous situation in which she lived in by reversing it, reassuring herself by the use of strength and objects that she could easily create and discard.

In order to consider another play developed subsequently by G., we must follow what occurred after the events described above. When the activities resumed after that semester's holidays, the Analyst was informed that G. had been transferred to another shelter. She was aware of the consequences that this new loss could have 
on G. and strove to get in contact with the new shelter and take the appropriate steps so that G. could continue to be seen in her office, since it would not be possible for the Analyst to go to this new shelter. The meetings resumed after a few months, and although G. would take two hours to go to the sessions, she rarely missed them. G. was accompanied by the "social mother" who lived with her and ten other children in one of the houses in this new shelter. In this circumstance, another type of play emerged offering indications on how the Analyst's demonstrations of availability and consistency impacted G. This involved constructions with wooden towers which were no longer destroyed. Here is how the Analyst describes it: These towers became more elaborate, colorful, and adorned with the wild animals from her box. The return of these animals also brought along short stories in which they were very brave and had to be vaccinated, otherwise they would die from their venom. In another story, the animals were "[...] very protected by army soldiers, so they would not flee from these homes."

It is very interesting that in the play described above, the satisfaction no longer was in destroying the constructions, but rather, in embellishing them. Wild animals also appeared on this occasion, but they were guarded by the soldiers. In this context, it is easy to understand that the play gives expression to the affective situations in which $G$. is living and is a way of dealing with them, that is, the Analyst perceived as someone with good aspects and, at the same time, threatened by G.'s wild side.

Moving now to G's last manifestation of playing, it occurred in a period in which her interest in drawings dominated. About the context in which this production occurred, it is important to emphasize the strengthening of her bond with the Analyst, as well as her beginning to go to school since she moved to the new shelter. Again, through G.'s play-in this case, drawing-we have indications of the positive impact that a more structured and consistent support had on her. In the beginning, the patient requested to copy drawings from the Analyst and then started making them from her own ideas. Human figures emerged, followed by houses, and regarding these, the analyst tells us: The bouses, in the beginning, were small and had little color, but over time, they increased in size and were then made with different materials like glue, toothpicks, colored tape, and sparkles. Her drawings became larger and gained intense colors, with interesting details and stories about her wishes of having a home with the entire family, with TV sets, food, and a lot of money in the safe for everyone. Her last play has one difference in relation to the previous two. The importance and significance of this difference may once again be considered in the light of some of Peirce's notions. Thus, in her second and third playing, we may say that what predominated was the firstness and secondness of the turbulent emotional experiences that she was living, which showed in the corresponding iconic and indexical signs that were part of her playing: firing of guns, constructionsdestructions, and then, towers that were elaborated but had wild animals nearby, which had to be guarded by soldiers. In the light of these Peircean elements, it is invaluable to contrast these productions with the latter playing-drawing. Although the signs that she used continued to be icons and indices, for example, through the images of the houses with their appliances and dwellers, it is easy to notice how they were derived from emotional situations in which the remarkable feature was the experience of a more stable and consistent continence. As a result, it is possible 
to consider that the images in the drawings, particularly those of the houses with families and their appliances, represent G.'s living situations with more stability and continuity, including, therefore characteristics of thirdness. The houses with relatives were images and indices of G.'s more stable world, but also symbols, in terms of Peirce, expressing the connection and greater complexity and consistency of the experiences that $\mathrm{G}$. was having in her life.

\section{Some final remarks}

One last point about our observations: although we have emphasized the importance given by Winnicott (1971) to the role of playing in the expression and handling of emotional situations, André Green (2005), in a conference presented at the Squiggle Foundation, drew attention to the fact that playing does not solely lead to healthy outcomes. In this sense, Green used the parallel of playing and dreaming, offering the example that although dreams tend to contribute to the elaboration of emotional experiences, they can also give way to nightmares. With the help of Peirce's semiotics, we will be able to use aspects of the clinical situations, mentioned so far, to better understand this difference pointed out by Green. What we observed in Beto's and G.'s cases will allow us to ponder this. For example, let us imagine that Beto had not had any analytic help and had remained confined to a level of firstness and secondness in actings of violence in his life and plays, the latter would work as a kind of reinforcement of his aggressiveness. We would not have, then, a play favoring health, but a continuous act of violence. Similarly, with G., there were several periods in which her play-life was repetitive in a reproduction and reaction to her traumatic experiences, with the use of corresponding icons and indices. Had it not been for the concrete demonstration of the persisting availability of the Analyst, associated with the support that G. found in a more consistent shelter and in the school, we might imagine that a play such as that in the phase of the shots and destruction of the castles by the patient would be associated with a delinquent career.

To finalize this paper, it will be convenient to return to Colapietro's (1989) notion regarding how the universal elements of Peirce's (1958) semiotics would constitute a basis of enormous value for the investigation of correlated processes on a psychological level. In fact, the basis referred to above helped to identify points in which the psychological value of Winnicott's concepts (1971) about transitional objects and phenomena could have important support and complementation by Peirce's philosophy. More specifically in relation to playing, we observed how Winnicott, in spite of his valuable contributions regarding these manifestations, did not develop a more detailed theorization about the role of signs in this area. We then considered how Peirce's semiotics could be applied in relation to these facets of playing, not only in terms of theorization, but also in various aspects of the clinical situations presented above.

The most fundamental purpose of the reflections developed in this work was to offer suggestions about opportunities for investigating the relationship between Peirce's philosophy and psychoanalysis - a rather large and open area with much to be explored. 


\section{References}

BION, W. R. Differentiation of the psychotic from the non-psychotic Personalities. In: Second Thoughts. Heinemann: London, 1967.

Cogitations. Karnac: London, 1992.

COLAPIETRO, V. Peirce's approach to the self. Suny Press: Albany, 1989.

. Notes for a sketch of a Peircean theory of the unconscious. In: The Transactions of Charles S. Peirce society. v. 31, n. 3, p. 482-506, 1995.

. Pragmatism and psychoanalysis - C. S. Peirce as a mediating figure. In: Cognitio: revista de filosofia, v. 7, n. 2, p. 189-205, 2006.

. Toward a pragmatist acknowledgment of the Freudian Unconcious. In: Cognitio: revista de filosofia, v. 9, n. 2, p. 187-203, 2008.

FISCHBEIN, S. V. The use of dreams in the clinical context: convergences and divergences: an interdisciplinary proposal. In: International Journal of Psychoanalysis, v. 92, p. 333-358, 2011.

FREUD, S. Beyond the Pleasure Principle. In: Standard Edition. Hogart Press: London, 1920. v. 18.

Green, A. Play and reflection in Donald Winnicott writings. Karnac Books: London, 2005.

GUIMARÃES Filho, P. D. Considerações sobre o uso de concepções de Peirce na Psicanálise. Trabalho apresentado em Reunião Científica da Sociedade Brasileira de Psicanálise de São Paulo. 2011.

IBRI, I. A. Kósmos Noetós. São Paulo: Paulus, 2015.

MULLER, J. Beyond the psychoanalytic dyad. London: Routledge, 1996.

Approaches to the semiotics of thought and feeling in Bion's work. In: Canadian Journal of Psychoanalysis. v. 13, p. 31-56, 2006.

PEIRCE, C. S. Collected Papers of Charles Sanders Peirce, v. 1-6, HARTSHORNE, Charles and WEISS, Paul (Eds.); v. 7-8; BURKS, Arthur W. (Ed.). Cambridge: Belknap Press of Harvard University Press. 1931-1958. (Cited as CP followed by volume and paragraph number).

SALOMONSSON, B. Semiotic transformations in psychoanalysis with infants and adults. In: International Journal of Psychoanalysis. v. 88, p. 1201-1221, 2007.

STEINER, R. Does the Peirce's semiotic model based on index, icon, symbol have anything to do with psychoanalysis? In: Language, symbolization and psychosis. AMBrosiO, G.; ARGENTIERI, S.; and CANESTRI, J. (Eds.). Karnac Books: London, 2007. p. 219-272.

VER EEKE, W. Peirce and Freud: the role of telling the truth in therapeutic speech. In: Peirce Semiotics and Psychoanalysis. MULLER, J.; and BRENT, J. (Eds.). Johns Hopkins: Baltimore, 2000. p. 84-101. 
WINNICOTT, D. W. Primitive Emotional Development. In: Through paediatrics to psychoanalysis. Karnac Books: London, 1992. p. 145-156.

Transitional objects and transitional phenomena. In: Playing and reality. Penguin Books: Harmondsworth, 1974. p. 1-30.

Playing: a theoretical statement. In: Playing and reality. Harmondsworth: Penguin Books, 1974. p. 44-61.

\section{Endereço/ Address}

Paulo Duarte Guimarães Filho

Rua João do Rio, 45

CEP: 05417-090 - Vila Madalena

São Paulo, SP - Brasil

Data de envio: 27-03-17

Data de aprovação: 21-04-17 
